\title{
Sorption of radionuclides onto minerals: Experiments and modelling
}

\author{
Anna Romanchuk ${ }^{1, *}$, Anna Semenkova ${ }^{1}$, Alena Larina ${ }^{1}$, and Stepan Kalmykov ${ }^{1}$ \\ ${ }^{1}$ Lomonosov Moscow State University, Department of Chemistry, 119991 Leninskie Gory, 1 bld.3, \\ Russia
}

\begin{abstract}
Sorption of various radionuclides such as $\mathrm{Cs}(\mathrm{I}), \mathrm{Eu}(\mathrm{III}) / \mathrm{Am}(\mathrm{III})$, $\mathrm{Np}(\mathrm{V}), \mathrm{U}(\mathrm{VI})$ and others onto iron oxide (goethite, hematite) and clay minerals (montmorillonite, kaolinite) was studied at wide experimental range $(\mathrm{pH}$ ionic strength, total radionuclides concentrations). In all case athermodynamic model for describing sorption onto studied minerals was built and successfully applied for all experiments. The required constants were calculated or verified from published data. For modelling sorption in mineral assemblages Component Additivity (CA) approach was successfully applied.
\end{abstract}

\section{Introduction}

Prediction of radionuclides behaviour in the environment in the places of long-term disposal of radioactive waste should include numerical methods for calculating the migration of different radionuclides (fission products, actinides) in addition to instrumental methods of monitoring of the current radiation situation. One of the major chemical processes that determine the behaviour of the radionuclides in geosphere is sorption on engineering barriers and products of its corrosion, host rocks, soil components, microorganisms, and etc.[1,2]. Thermodynamic modelling using a surface complexation modelling approach is currently the state-of-the art tool for predicting the interaction of radionuclides with different minerals under different geochemical conditions. Therefore, reactive transport modelling that takes into account both chemical interactions of radionuclide as well as its transport is still challenging for the moment. One of the most important tasks in this is creation of database of reliable constants of reactions and other numerical characteristic. The aim of this work was improvement of methods of experimental determination of sorption constants by surface complexation modelling (SCM).

\section{Experiments}

The two main groups of minerals that were chosen for these experiments are iron oxide/hydroxide and clay minerals. The list of the studied samples presented in Table 1.

\footnotetext{
*Corresponding author: romanchuk.anna@gmail.com
} 
Synthesized iron oxides/hydroxides were specially prepared. Different clay samples were studied in order to examine effect of structural features of clay minerals (structure types 2:1 and $1: 1)$, interlayer cations $(\mathrm{Na} / \mathrm{Ca} / \mathrm{Li}$-forms of montmorillonite), surface area and presence of the accessory minerals (iron oxides, calcite, quartz) on radionuclide sorption. Various techniques, e.g. XRD, XRF, BET absorption, Mossbauer etc. were used to characterize these clays.

Table 1. Properties of studied samples for sorption experiments.

\begin{tabular}{|c|c|c|}
\hline Sample & $\begin{array}{c}\text { Surface area, } \\
\mathrm{m}^{2} / \mathrm{g}\end{array}$ & Composition \\
\hline $\begin{array}{c}\text { Synthesized } \\
\text { goethite }\end{array}$ & 107 & $\alpha-\mathrm{FeOOH}$ \\
\hline $\begin{array}{c}\text { Synthesized } \\
\text { hematite }\end{array}$ & $35-\mathrm{Fe}_{2} \mathrm{O}_{3}$ \\
\hline $\begin{array}{c}10^{\text {th }} \text { Khutor } \\
\text { bentonite } \\
\text { (Khakassia, Russia) }\end{array}$ & 15 & $\begin{array}{c}\text { Na-form of montmorillonite }(65 \%)+\text { quartz } \\
(16 \%) \text { and others }\end{array}$ \\
\hline $\begin{array}{c}\text { Kutch bentonite } \\
\text { (India) }\end{array}$ & 115 & $\begin{array}{c}\text { Na- and Ca- forms of montmorillonite }(90 \%) \\
+ \text { goethite }(3 \%) \text { and others }\end{array}$ \\
\hline $\begin{array}{c}\text { Kutch purified } \\
\text { bentonite }\end{array}$ & 150 & $\begin{array}{c}\text { Na- form of Fe-montmorillonite(with } \\
\text { relatively high structural iron content) }\end{array}$ \\
\hline $\begin{array}{c}\text { FEBEX bentonite } \\
\text { (Spain) }\end{array}$ & 45 & $\begin{array}{c}\text { Ca- }, \text { Mg- and Na- forms of montmorillonite } \\
(94 \%) .\end{array}$ \\
\hline $\begin{array}{c}\text { Kaolinite } \\
\text { (Aldrich) }\end{array}$ & 6 & kaolinite (98\%) \\
\hline
\end{tabular}

The sorption regularities of various radionuclides (Cs(I), Eu(III)/Am(III), Np(V), U(VI)) were studied in wide experimental range: different $\mathrm{pH}$ values, different radionuclides concentration and different ionic strength. Sorption data were modeled using a geochemical code PHREEQC.

\section{Results and discussion}

The sorption behaviour various radionuclides onto goethite and hematite was studied producing sorption isotherms and $\mathrm{pH}$-dependences. Figure 1 shows one of the examples of the produced experimental data. Different model options including surface site types and varying of composition of surface species were examined. Validation of the obtained results was carried out by applying calculated constant to the experimental data in extreme different condition. The most difficult problem in SCMapproach is the lack of knowledge about a structure of sorbent surface (concentration of "strong" and "weak" sorption sites) and stoichiometry of surface complexes. Sorption isotherms obtained in a wide range of cation concentrationswere used to solve this problem. Collective modelling of sorption data for different radionuclides resulted in creation of uniform model for sorption onto goethite and hematite. The concentration of strong and weak sorption sites was calculated on this base.

Sorption of $\mathrm{Am}(\mathrm{III})$ and $\mathrm{Np}(\mathrm{V})$ onto goethite was examined at high ionic strength (up to $2.5 \mathrm{M} \mathrm{NaNO}_{3}$ ). Absence of any significant changes was determined in values of sorption was determined. 


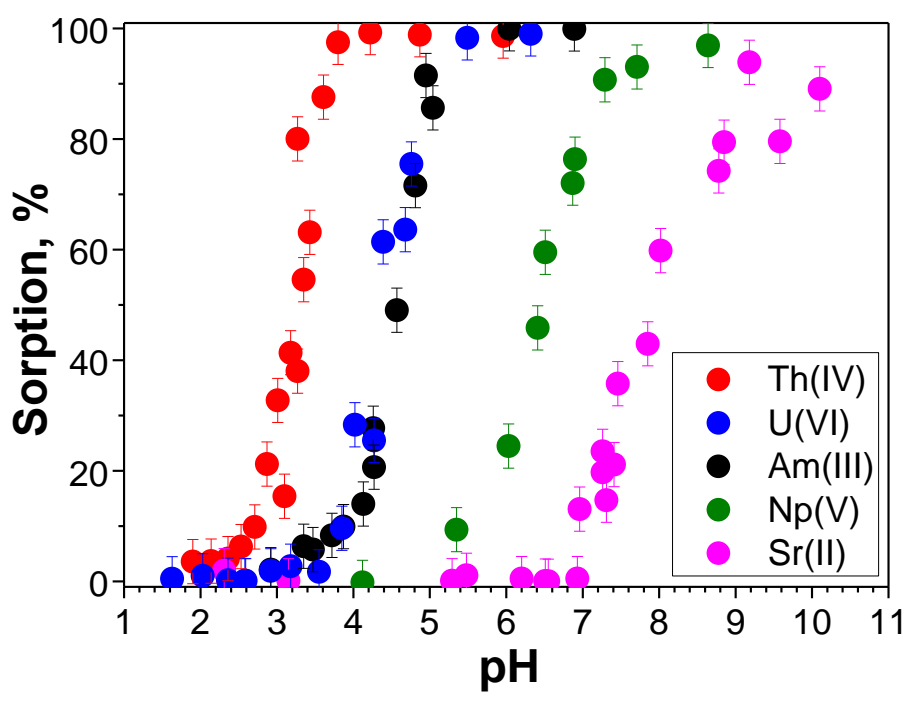

Fig. 1. Sorption of $\mathrm{Th}(\mathrm{IV}), \mathrm{U}(\mathrm{VI}), \mathrm{Am}(\mathrm{III}), \mathrm{Np}(\mathrm{V})$ and $\mathrm{Sr}(\mathrm{II})$ onto $\alpha$-FeOOH $\left([\mathrm{Th}(\mathrm{IV})]=4 \cdot 10^{-14} \mathrm{M},[\mathrm{U}(\mathrm{VI})]=9 \cdot 10^{-8} \mathrm{M},[\mathrm{Am}(\mathrm{III})]=6 \cdot 10^{-10} \mathrm{M},[\mathrm{Np}(\mathrm{V})]=1 \cdot 10^{-14} \mathrm{M},[\mathrm{Sr}(\mathrm{II})]=\right.$ $\left.3 \cdot 10^{-11} \mathrm{M},[\alpha-\mathrm{FeOOH}]=0.3 \mathrm{~g} / \mathrm{L}, \mathrm{I}=0.1 \mathrm{M}\right)$.

The sorption behaviour of $\mathrm{Np}(\mathrm{V})$ onto different clays and clay minerals was compared[3,4]. At $\mathrm{pH}>5$, the interlayer cations in montmorillonite had no influence on sorption. The dominant mechanism in this $\mathrm{pH}$ range was complexation with edge surface sites. As a result, clay minerals with 2:1 type with different interlayer cations and 1:1 type demonstrated similar sorption profiles. The most influential characteristic of clays that changed the $\mathrm{Np}(\mathrm{V})$ sorption dramatically was the presence of iron oxyhydroxide as an accessory mineral.

The sorption of Cs(I) onto different clays was studied [5]. Two types of sorption sites were distinguished for montmorillonite. It was found that the sorption properties of the highly selective sites highly depended on the clay deposit. The competition of $\mathrm{Cs}(\mathrm{I})$ with different cations, including $\mathrm{H}^{+}, \mathrm{Ca}^{2+}$ and $\mathrm{Mg}^{2+}$, was sufficiently accounted using experimental data.

No significant differences were observed for trace $\mathrm{Eu}(\mathrm{III})$ concentration at low ionic strengths. Its sorption was quantitative for different studied clay samples over a wide $\mathrm{pH}$ range at $[\mathrm{Eu}]=10^{-11} \mathrm{M}$ and $\mathrm{I}=0.01 \mathrm{M}$. With increasing ionic strength and total europium concentration, the sorption properties of different clay samples became distinct. Similar to $\mathrm{Np}(\mathrm{V})$ the noticeable influence of trace amount goethite as impuritieson Eu(III) sorption was found.

\section{Conclusion}

A thermodynamic model for describing the radionuclides sorption onto iron oxide/hydroxide and clay minerals over a wide range of cation concentrations and ionic strength was built and successfully applied for all experiments. The required constants were calculated or verified from published data. For raw clay samples with presence of goethite as accessory minerals ComponentAdditivity (CA) approachwas successfully applied for modelling.

This work was supported by the Russian Science Foundation (grant number 16-13-00049). 


\section{References}

1. D.A. Kulik, Rev. Mineral. Geochemistry, 70, 125-180 (2009)

2. H. Geckeis, J. Lützenkirchen, R. Polly, T. Rabung and M. Schmidt, Chem. Rev., 113, 1016-1062 (2013)

A. Semenkova, A.Y. Romanchuk, V.V. Krupskaya, B.V. Pokidko, O.V. Dorzhieva, A.V. Sobolev, I.A. Presnyakov, P.K. Verma, P.K. Mohapatra and S.N. Kalmykov, Appl. Geochemistry, 92, 1-8 (2018)

3. P.K. Verma, A.Y. Romanchuk, I.E. Vlasova, V.V. Krupskaya, S.V. Zakusin, A.V. Sobolev, A.V. Egorov, P.K. Mohapatra and S.N. Kalmykov, Appl. Geochemistry, 78, 74-82 (2017)

4. A.S. Semenkova, M.V. Evsiunina, P.K. Verma, P.K. Mohapatra, V.G. Petrov, I.F. Seregina, M.A. Bolshov, V.V. Krupskaya, A.Y. Romanchuk and S.N. Kalmykov, Appl. Clay Sci., 166, 88-93 (2018) 